$\xi=-1$

\title{
Characterization of Cr/Ag Bi-Layer thin Metal Contacts Sputter Deposited on $N$-Type Si Semiconductor
}

\author{
Ahmad Hadi Ali ${ }^{1 *}$, Nurul Syafiqah Pauzi \\ ${ }^{1,2}$ Semiconductor Optoelectronics Research Group, Department of Physics and Chemistry, Faculty of Applied Sciences and Technology, \\ University Tun Hussein Onn Malaysia, 84600, Pagoh Educational Hub, Johor \\ *Corresponding author E-mail: ahadi@uthm.edu.my
}

\begin{abstract}
Good electrical conductivity of metal contacts on semiconductor are very crucial in determining quality of the energy conversion efficiency. This paper reports on the $\mathrm{Cr} / \mathrm{Ag}$ thin metal contacts properties sputter deposited on $\mathrm{n}$-type $\mathrm{Si}$. The metal contacts were characterized based on the morphological and electrical properties. The surface morphology of metal contacts was characterized by using atomic force microscope (AFM) and resulted in increment of the surface roughness from $1.35 \mathrm{~nm}$ to $9.21 \mathrm{~nm}$ at the thickness of $20 \mathrm{~nm}$ to 100 $\mathrm{nm}$. The electrical characteristics were characterized by using four-point probe system. From the measurement, the lowest electrical resistivity was measured as $1.19 \times 10^{-6} \Omega-\mathrm{cm}$ at Ag thickness of $100 \mathrm{~nm}$. Whereas the electrical conductivity of the thin metal contact was obtained as $8.40 \times 10^{5} \Omega-\mathrm{cm}^{-1}$ at Ag thickness of $100 \mathrm{~nm}$. From the analysis, it is clearly shown that as the Ag thin metal thickness gets thicker, the surface roughness gets rougher thus resulting in the improvement of the electrical characteristics of the $\mathrm{Si} / \mathrm{Cr} / \mathrm{Ag}$ contacts.
\end{abstract}

Keywords: Cr/Ag; Metal contacts; thin films; Si semiconductor; sputter.

\section{Introduction}

Metal material is a good electrical conductor especially gold $(\mathrm{Au})$, copper $(\mathrm{Cu})$, titanium $(\mathrm{Ti})$, aluminium $(\mathrm{Al})$, nickel $(\mathrm{Ni})$ and argentum (Ag). The conductivity of each metal material is differed by their physical structure itself which is formed by the movement of the free electron of each metal material and thus affect the electrical conductivity when there is a presence of the potential energy through it. All of these metal material has their own unique properties such as $\mathrm{Ni}$ which is able to reduce the channel between the drain and source gate which will decreased the resistivity of the device and thus making this metal material to become important in complementary metal oxide semiconductor (CMOS) device industry [1]. While for $\mathrm{Ti}$, is its grain refinement formation that produce the smoother surface of deposited thin film and also has a high resistance to the corrosion that enable the metal contact to be applied in high thermal energy device such as in the laser technology [2]. Then, for the Au metal material, it has high malleability, ductility, resistance to corrosion and also one of the good electrical conductor material and has been widely used in metal contact technology [3]. As for Ag, it will produce neutral color in the range of visible light spectrum and also make it as an ideal candidates for the low thermal emissivity that is reported by Ding et al.[4]. But after all, by comparing the electrical conductivity as well as their electrical resistivity, Ag offers as a good candidate to be used in metal contact technology due to its lowest electrical resistivity and highest electrical conductivity which are $1.59 \times 10^{-8}$ $\Omega-\mathrm{m}$ and $6.30 \times 10^{7}(\Omega-\mathrm{m})^{-1}$ respectively among other materials. The electrical and structural properties of thin metal films can be affected by a large number of parameters such as deposition time, surface morphological, thickness and type of substrates. Therefore, the composition of the two or more thin metal film phases may give benefits to the metal contact technology such as an improve- ment in morphological, optical and electrical properties of the deposited multilayers thin film. Many researchers have reported on the bi-layer metal contacts such as $\mathrm{Au} / \mathrm{Cu}$, and $\mathrm{Ni} / \mathrm{Cr}, \mathrm{Cr}-\mathrm{C} / \mathrm{Ag}$ and $\mathrm{Ni} / \mathrm{Ag}$ [5], Ti/Al, $\mathrm{Cr} / \mathrm{Pd}[6]$ and $\mathrm{Ni} / \mathrm{Au}$. For the $\mathrm{Au} / \mathrm{Cu}$ bi-layer thin film which is both in the transition metal material, the bi-layer thin film increases the grain size during the increment of the thin film thickness and thus decreased in the electrical resistivity during the annealing treatment process. Their behavior tends to be stable which is reported by Novelo et al. [7]. For Ni/Cr bi-layer thin film, Cheng et al. [8] reported that the resistance of the thin films is non-linearly decreased with the increased of the deposition rate and had no apparent variations during the deposition time increment.

In electronics industry, multilayer thin film is used as metallic contacts or as a relays in micro-electrochemical systems (MEMS). The selection of the sub-layers sandwich depends on its MEMS application. $\mathrm{Au}, \mathrm{Ag}$ and $\mathrm{Cu}$ are commonly used as a conduction layer while $\mathrm{Cr}$, Ti and $\mathrm{Pt}$ are employed as an adhesion layer which is acted as a diffusion barrier for the electric charge particles. In the research reported by Bassiri [9], the performance in electrical and mechanical behavior of the contact relays also depends on the adhesion layer such as Ti or Cr. Between these two materials, $\mathrm{Cr}$ layer seems to be more favorable intermediate layer as compared to $\mathrm{Ti}$ due to the less increased in electrical resistivity. For $\mathrm{Cr}-\mathrm{C} / \mathrm{Ag}$ multilayer deposited thin film, Folkenant et al. [10] stated that the resistance of the deposited thin film decreased with the addition of $\mathrm{Ag}$ nanoparticles which enable the $\mathrm{Cr}-\mathrm{C} / \mathrm{Ag}$ thin films to be applied in the electric contact application. This metal carbide transition material is one of the potential candidates for the applications of high hardness, high wear resistances, low friction as well as high corrosion resistance conditions. Besides, it also gives better contact properties. 
Deposition of metal contact semiconductor substrate can be done by various technique such as physical vapor deposition (PVD) and chemical vapor deposition (CVD). Mostly used PVD technique are thermal evaporation and sputtering, while the metal organic chemical vapor deposition is one example of the CVD technique. Thermal evaporation technique is the most simple and low cost technique to be used in deposition process, but it resulted poor adhesion contact while MOCVD technique is highly cost as compared to sputtering technique. In the other hand, sputtering technique is the most favorable deposition technique because this technique is easily to handle and the thickness of the metal deposition contact can be controlled which can improve the resistivity of the contact.

This paper reports on the properties of $\mathrm{Cr} / \mathrm{Ag}$ thin metal contacts sputter deposited on n-type $\mathrm{Si}$ at different $\mathrm{Ag}$ thicknesses. The metal contacts were characterized based on the morphological and electrical properties.

\section{Methodology}

In this study, n-type $\mathrm{Si}$ is chosen as a substrate as $\mathrm{Si}$ offers a good quality, low cost and vastly used in semiconductor optoelectronics industry. The Si wafer was cut into small pieces of 1.0 $\times 1.0 \mathrm{~cm}^{2}$ and cleaned by using acetone, IPA and finished by DI water to remove surface contamination. After cleaning, very thin layer of intermediate layer of $\mathrm{Cr}(5 \mathrm{~nm})$ was deposited on the $\mathrm{Si}$ substrate followed by Ag top layer at different thicknesses. The deposition process of the thin metal contact on the substrates were being done by using RF sputtering system. For the thickness of $\mathrm{Ag}$ metal with the purity of $99.99 \%$, it was varied at 20 , 40, 60, 80, 100, and $120 \mathrm{~nm}$ each. The thickness of the deposited thin film was measured based on the sputtering rate of the sputtering system.

The surface morphological and electrical properties of the metal contacts were characterized by using atomic force microscopy (AFM) and four-point probe. The surface morphological characterization by AFM were scanned by using tapping mode. The metal contacts were characterized based on its electrical resistivity and sheet resistance by using four-point probe. The conductivity then was determined by calculating the reciprocal of the resistivity.

\section{Results and Discussion}

Surface morphological of the $\mathrm{Cr} / \mathrm{Ag}$ metal contacts were characterized in 2D and 3D by using AFM as shown in Fig. 1. From the analysis, as the thickness of the thin film increases, the surface of the thin film becomes rougher from 1.35 to $9.21 \mathrm{~nm}$ at thickness of 20 and $100 \mathrm{~nm}$ respectively, as shown in Fig. 2. The formation of the coarse grain seems to be unavoidable as the thicker Ag metal material were deposited. But, it is significant to the research conducted by Loka and Lee [12] that stated the bi-layer surface was crystallized and forming a coarse grain resulted from the increment of the Ag metal material thickness. Thus, the morphological surface of the bi-layer thin film will be rougher. Besides that, Changwon et al. [13] also convinced that the additional roughness occurred is due to the dense wrinkles and bumps formation throughout the surface during the vacuum phase of the sputtering process that will deform the bi-layer thin film surface.

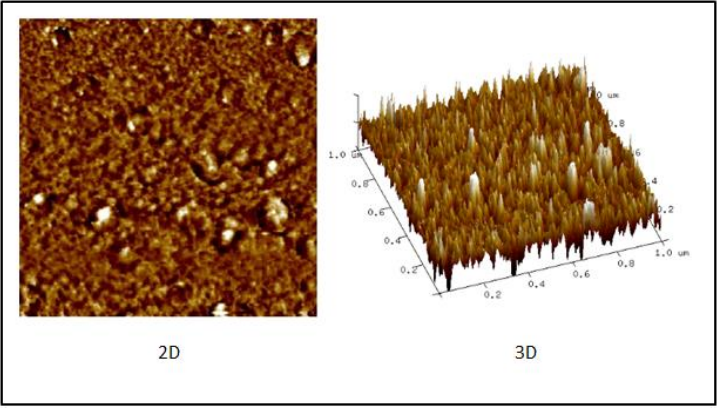

(a)

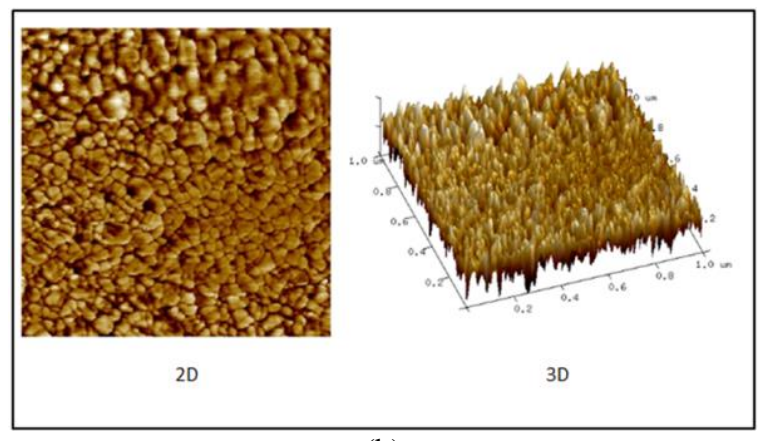

(b)

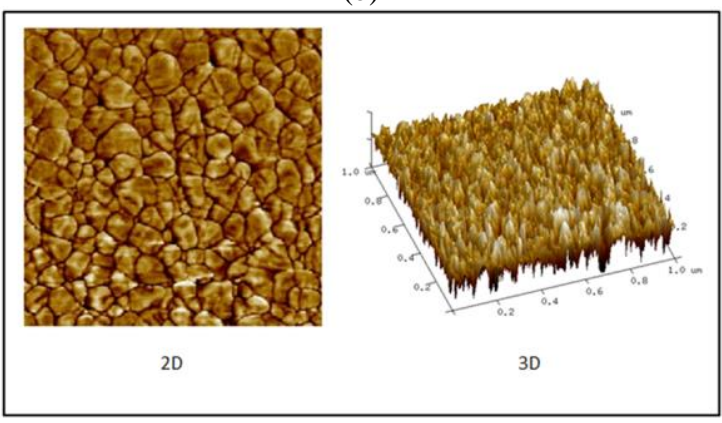

(c)

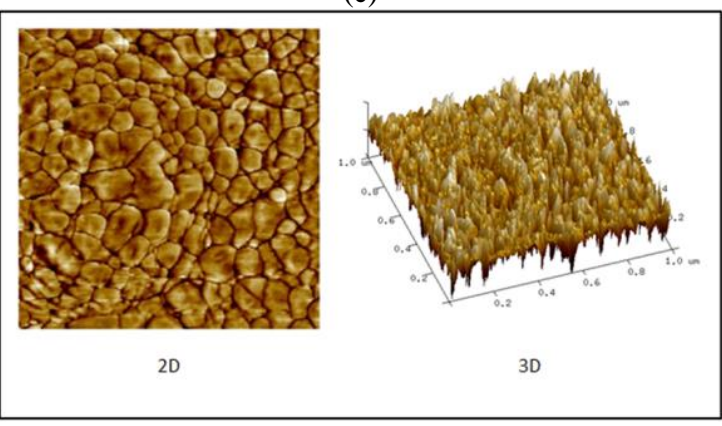

(d)

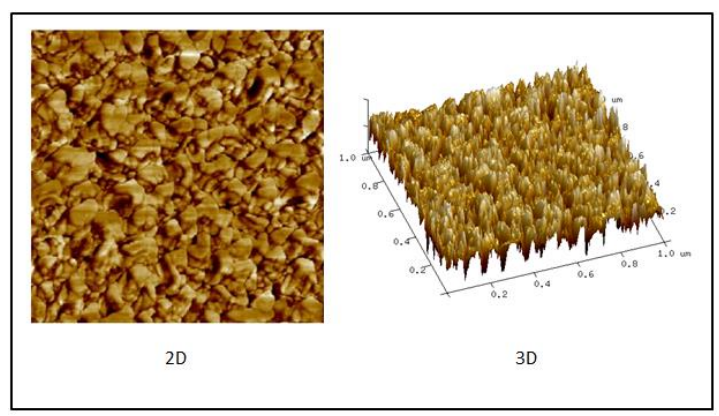

(e) 


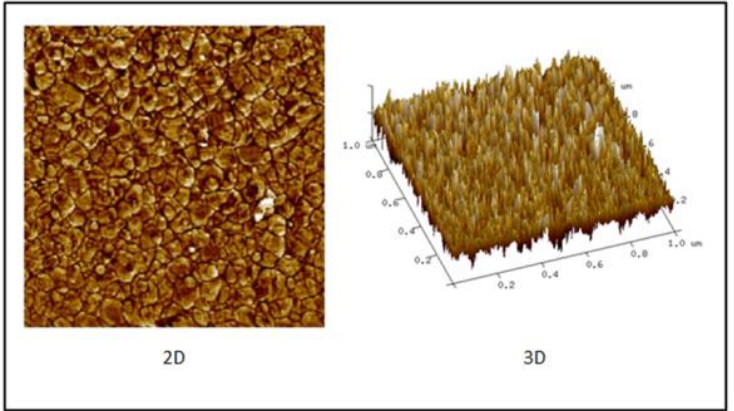

(f)

Fig. 1: Surface morphological of $\mathrm{Cr} / \mathrm{Ag}$ thin metal contacts sputter deposited on n-type Si scan bay AFM in 2D and 3D (a) $20 \mathrm{~nm}$ (b) $40 \mathrm{~nm}$ (c) $60 \mathrm{~nm}$ (d) $80 \mathrm{~nm}$ (e) $100 \mathrm{~nm}$ (f) $120 \mathrm{~nm}$.

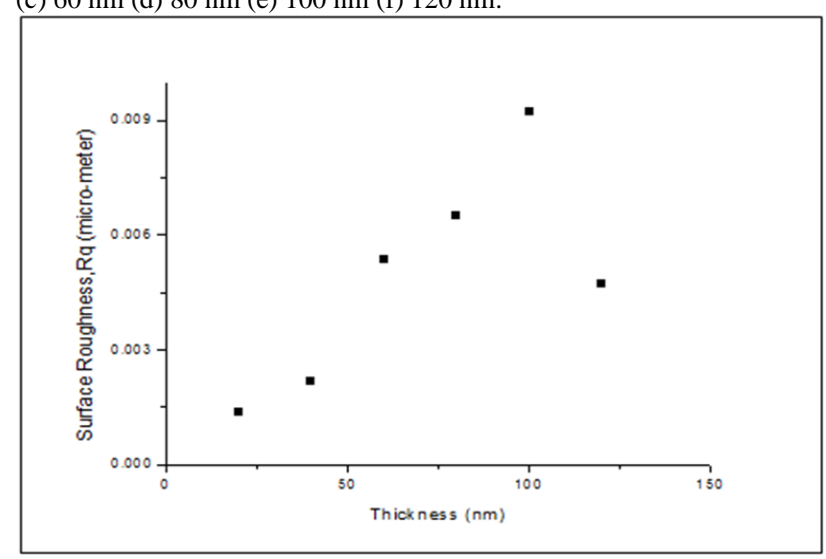

Fig. 2: Surface roughness, $R_{\mathrm{q}}$ at different $\mathrm{Ag}$ thickness.

The electrical characterization was performed by using four-point probe. Fig. 3 shows the relation between the resistivity of Ag thin metal film at different deposited thickness. It can be seen that, as the thickness increased from 20 to $100 \mathrm{~nm}$, its electrical resistivity was continuously decreased which follows the theoretical data. However, the resistivity $(\rho)$ of thin film is slightly increased at the thickness of $120 \mathrm{~nm}$ which is $2.82 \times 10^{-6} \Omega-\mathrm{cm}$. This may be due to the existence of the impurities that may increase the resistance to the electrical current to pass through its surface. Generally, the resistivity of the bulk $\mathrm{Ag}$ is the lowest as compared to other metal material which is $1.59 \times 10^{-6} \Omega-\mathrm{cm}$. From the experiment, after being deposited on $\mathrm{Si} / \mathrm{Cr}$, the lowest electrical resistivity of the thin film is $1.19 \times 10^{-6} \Omega-\mathrm{cm}$ at $100 \mathrm{~nm}$.

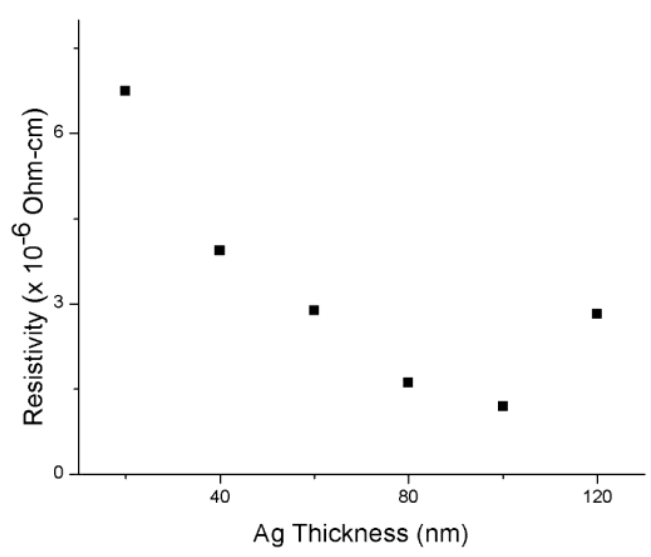

Fig. 3: Electrical resistivity of $\mathrm{Cr} / \mathrm{Ag}$ metal thin films at different $\mathrm{Ag}$ thicknesses.

Further analysis shows the electrical conductivity of the Ag thin films at $100 \mathrm{~nm}$ is the highest of $8.40 \times 10^{5}(\Omega-\mathrm{cm})^{-1}$ as compared to other thickness, as shown in Fig. 4 . The presence of the very thin deposited $\mathrm{Cr}$ under-layer between $\mathrm{Si}$ substrate and Ag top layer which act as a buffer layer as well as good adhesive to upper contact layer. This buffer layer will prevent the charge carrier from being ejected from the thin film surface and depleted. Thus, will increased the electrical conductivity as the resistivity of the metal thin films decreases.

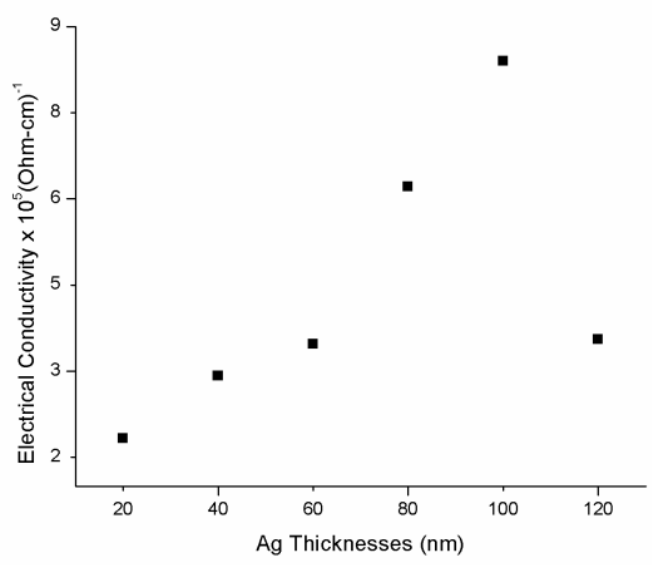

Fig. 4: Electrical conductivity of $\mathrm{Cr} / \mathrm{Ag}$ sputter deposited on $\mathrm{Si}$ at different Ag thicknesses.

Fig. 5 shows the sheet resistance, $R_{\mathrm{S}}$ of the $\mathrm{Si} / \mathrm{Cr} / \mathrm{Ag}$ thin metal contacts against the different thickness of $\mathrm{Ag}$ material deposited on $\mathrm{Si} / \mathrm{Cr}$ substrates. Similar to the electrical resistivity of the deposited thin film, the sheet resistivity, $R_{\mathrm{s}}$ of the thin film were decreased as the thickness of thin film increased. Based on the analysis, the highest sheet resistivity of $\mathrm{Si} / \mathrm{Cr} / \mathrm{Ag}$ thin film is at the thickness of $20 \mathrm{~nm}$ which is $3.37 \times 10^{-1} \Omega / \mathrm{sq}$ while the lowest sheet resistivity, $R_{\mathrm{s}}$ was at the thickness $100 \mathrm{~nm}$ which is $1.19 \times$ $10^{-1} \Omega /$ sq.

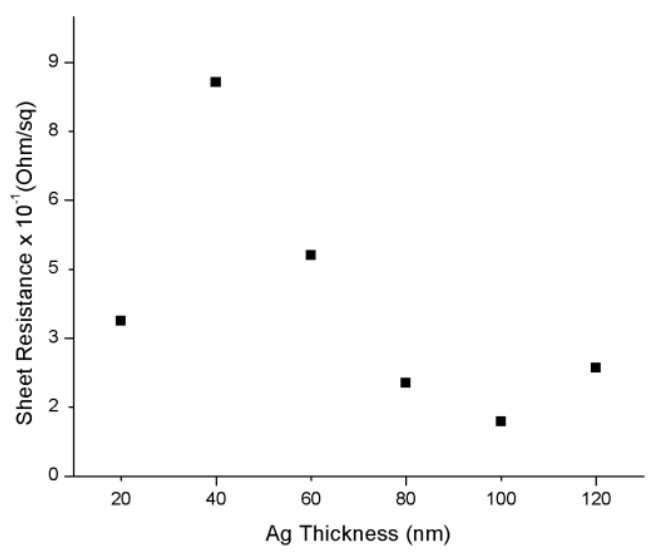

Fig. 5: Sheet resistance of the $\mathrm{Si} / \mathrm{Cr} / \mathrm{Ag}$ thin metal contacts.

Based on the electrical properties characterization, the electrical resistivity of the deposited thin film depends on the thickness of the metal contact. The electrical resistivity $(\rho)$ can be expressed as

$\rho=\rho_{p}+\rho_{m}+\rho_{r}+\rho_{i}+\rho_{s}$

where $\rho_{p}, \rho_{m}, \rho_{r}, \rho_{i}, \rho_{s}$ represents the electrical resistivity caused by photon, impurity, defects, grain boundary and the surface scattering effect, respectively. The resistivity caused by impurity and defects can be classified as the same deposition conditions except the deposition time. While, for the resistivity caused by the surface 
scattering should not play a role in this condition due to the lower of electron mean free path compared to the varied deposition thickness that ranging from 20, 40, 60, 80, 100 and $120 \mathrm{~nm}$ [9]. Experimentally, as the thickness of the thin film increased, the electrical resistivity is continuously decreased from $20 \mathrm{~nm}$ to 100 $\mathrm{nm}$. This is due to an increment of the grain size that will reduce the grain boundary thus decreasing the electrical resistivity of the thin film. But, there were small increment of the electrical resistivity at the thickness of $120 \mathrm{~nm}$. This may due to the present of the impurities that will decreased the charge carrier concentration. The electrical conductivity shows an increment as if it is inversely proportional to the electrical resistivity. While, the sheet resistance was decreased as the thickness of the thin film increased.

\section{Conclusion}

The $\mathrm{Cr} / \mathrm{Ag}$ thin metal contacts show good surface morphological and electrical properties as the thicknesses increases. The surface roughness was become rougher which is 1.35 to $9.21 \mathrm{~nm}$ as the thickness increased from $20 \mathrm{~nm}$ to $100 \mathrm{~nm}$ respectively as well. The electrical resistivity depends on the thickness of the thin film and were decreased from $6.74 \times 10^{-6}$ to $1.19 \times 10^{-6} \Omega$-cm at the thickness of 20 and $100 \mathrm{~nm}$, respectively. The electrical conductivity was increased from $1.83 \times 10^{5}$ to $8.40 \times 10^{5}(\Omega-\mathrm{cm})^{-1}$ as the $\mathrm{Ag}$ thickness increases to $100 \mathrm{~nm}$. In addition, the sheet resistivity was decreased from $3.37 \times 10^{-1}$ to $1.19 \times 10^{-1} \Omega /$ sq.

\section{Acknowledgement}

This research was funded by Fundamental Research Grant Scheme (FRGS) with grant No. 1600 from Malaysian Ministry of Higher Education and Incentive Grant Scheme for Publication (IGSP) with grant No. U670 by Universiti Tun Hussein Onn Malaysia. Thanks also to Physics Laboratory, Faculty of Applied Science and Technology, and Microelectronics \& NanotechnologyShamsuddin Research Centre (MiNT-SRC) for the facilities provided.

\section{References}

[1] Cheng SL, Lai RH, Huang YD \& Lin HC (2017), Interfacial reactions and microstructural evolution of periodic Ni nanodot arrays on $\mathrm{N}_{2}{ }^{+}$implanted amorphous Si substrates. Applied Surface Science, 399, 313-321.

[2] Jin J, Zhu Z \& Zheng D (2017), Influence of Ti content on the corrosion properties and contact resistance of CrTiN coating in simulated proton exchange membrane fuel cells. International Journal of Hydrogen Energy, vol. 42, issue. 16, 11758-11770.

[3] Kim M, Kim K, Lee D, Lee S \& Lee J (2015), Effects of rapid thermal annealing for E-beam evaporated $\mathrm{Ag}$ films on stainless steel substrates. Surface \& Coatings Technology, 278, 18-24.

[4] Ding G, Clavero C, Schweigert D \& Le M (2015), Thickness and microstructure effects in the optical and electrical properties of silver thin films. AIP Advances, 5, 117234.

[5] Ali AH, Hassan Z \& Shuhaimi A (2014), Improved Optoelectronics Properties Of Ito-Based Transparent Conductive Electrodes With The Insertion Of Ag/Ni Under-Layer. Applied Surface Science, Vol. 315, 387-391.

[6] Ahmad RA, Ali AH, Isiyaku AK \& Bhari BK (2017), Improved Resistivity And Surface Morphology Of Laser Treated Cr/Pd Metal Contact Sputter Deposited On Si", Journal of Science and Technology, Vol. 9, 3, 101-105.

[7] Novelo TE, Alonzo-Medina GM, Amézaga-Madrid P \& Maldonado RD (2017), Surface Morphology and Electrical Resistivity in Polycrystalline Au/Cu/Si (100) System. Journal of Nanomaterials, Vol. 2017, 1-8.

[8] Cheng H, Chen Y, Li C \& Li P (2016), Developments of Cr-Si and Ni-Cr Single-Layer Thin-Film Resistors and a Bi-Layer Thin-Film Resistor with Adjustable Temperature Coefficient of Resistor, Materials Sciences and Applications, 7, 895-907.
[9] Bassiri G (2006), Diffusion effect of intermetallic layers on adhesion and mechanical properties of electrical contacts. Fundamentals of Nanotechnology, 1-10.

[10] Folkenant M, Nygren K, Malinovskis P, Palisaitis J, Persson PO A, Lewin E \& Jansson U (2015), Structure and properties of $\mathrm{Cr}-\mathrm{C} / \mathrm{Ag}$ films deposited by magnetron sputtering. Surface \& Coatings Technology, 281,184-192.

[11] Moghri Moazzen MA, Taiebyzadeh P \& Borghe SM (2017), Electrical and structural properties of the Ta/Ag thin films prepared by DC magnetron sputtering. IOP Conf. Series: Journal of Physics: Conf. Series 869, 012031.

[12] Loka C \& Lee KS (2017), Reflectance changes of Fe and Cr doped Ag thin films deposited by magnetron sputtering. Thin Solid Films, Vol. 641, 73-78.

[13] Changwon L, Robertson CS, Nguyen AH, Kahraman M \& Wachsmann-hogiu S (2015), Thickness of a metallic film , in addition to its roughness, plays a significant role in SERS activity," Scientific Report, 5, 11644 